\title{
RADIODENSITY OF MEDIAL CORONOID PROCESS IN DOGS
}

\author{
Armands Vekšins, Oskars Kozinda \\ Latvia University of Life Sciences and Technologies, Latvia \\ armands.veksins@llu.lv
}

\begin{abstract}
The aim of this study was to detect radiodensity of a medial coronoid process of elbow joints with a medial coronoid disease and normal elbow joints in dogs. The study includes 91 large and giant breed dogs at the age from 6 to 30 months. Medial coronoid disease was diagnosed in 65 dogs and 26 dogs had normal elbow joints. Computed tomography was performed with Philips MX - 16 CT scanner and imaging data analysis performed using Horos v.2.2.0 software. CT technical data included $140 \mathrm{kVp}, 250 \mathrm{mAs}, 1$ second rotation time and 0.75 slice thickness. The density of a medial coronoid process (MCP) was measured by two unrelated measurement methods. The study describes Hounsfield unit values in different areas of MCP in normal elbow joints and in medial coronoid disease affected joints. In $91.8 \%$ cases, MCP subchondral sclerosis observed with MCP fragmentation or fissure. We conclude that both bone density measurement methods are suitable for veterinary diagnostic imaging and can be used to evaluate canine elbow joints.
\end{abstract}

Key words: canine, elbow joint, computed tomography, coronoid disease.

\section{Introduction}

Medial coronoid disease (MCD) is an inherited disorder of canine elbow joints that affects young, large and fast-growing dog breeds such as German shepherd dogs, Labrador retrievers, Rottweilers and Bernese mountain dogs (Remy et al., 2004). Most of the affected dogs clinically are recognized to live for the first 12 months and they are lame with MCD affected limb (Vermote et al., 2010). Because of intermittent lameness, often MCD has been diagnosed also in older dogs (as cited in Samoy, Gielen, \& Bree, 2011). An etiology of an MCD is not fully clear despite previous studies. It is known that MCD is an inherited and multifactorial disease. As one of the most common causes are considered disturbance of a medial coronoid process (MCP) endochondral ossification and elbow joint incongruity (Gemmill et al., 2006; Lavrijsen et al., 2014). A medial coronoid disease characterized by a several pathological changes - most common fragmentation or fissuring of $\mathrm{MCP}$, subchondral sclerosis and osteophyte proliferation (VillamonteChevalier et al., 2015).

Subchondral sclerosis is a thickening of a bone and reflecting an imbalance in the rate of bone apposition and resorption and that indicates injury of cartilage layer injury (Hurlbeck et al., 2014). In radiology to describe bone sclerosis a term radiodensity - opacity to the X-ray portion of the electromagnetic spectrum is used. It is considered that subchondral sclerosis is an early indicator of MCD (Smith et al., 2009). MCP sclerosis is often detected together with a blunting at the cranial edge of the MCP. Elbow joints in most cases are evaluated radiographically and subchondral sclerosis is rated by visually perceptible changes (Smith et al., 2009).

Medial coronoid process subchondral sclerosis is often seen together with a medial coronoid disease and mostly diagnosed with visual changes. The aim of the study was to detect the radiodensity of a medial coronoid process of elbow joints with a medial coronoid disease and normal elbow joints in dogs. To fulfill the aim, we set objectives: (1) to determine the radiodensity (measured in Hounsfield units, HU) of a medial coronoid process in dogs by two unrelated methods; (2) to evaluate the effect of age, bodyweight and breed on MCP radiodensity; (3) compare HU between normal elbow joints and medial coronoid disease affected joints.

\section{Materials and Methods}

The study was performed at LLU Veterinary hospital during the time period from 2014 to 2017. The study includes 91 large and giant breed dogs, at the age from 6 to 30 months. Before computed tomography (CT) scanning, all animals were clinically examined. Examination included: (1) registration; (2) patient history; (3) general and orthopedic examination. All CT scans were performed by owner's request. Included dog breeds are presented in Table 1.

Computed tomography was performed in a general anesthesia. Dogs were pre-anaesthetized with medetomidine hydrochloride $0.01 \mathrm{mg} \mathrm{kg}^{-1}$, propofol 3mg kg-1 and then intubated. Anesthesia was maintained with isoflurane $1000 \mathrm{mg} \mathrm{g}^{-1}$ and $100 \%$ oxygen. Computed tomography of elbow joints performed with Philips MX - 16 CT scanner with $140 \mathrm{kVp}, 250 \mathrm{mAs}, 1$ second rotation time and 0.75 slide thickness. During examination, patients were positioned ventrodorsally with parallel extended front limbs. After CT examination dogs were divided into two groups: (1) dogs with a medial coronoid disease; (2) healthy dogs. All CT results were analyzed with a Horos v2.2.0 medical software.

Bone radiodensity was measured by two unrelated methods. On the technique (A) MCP region of interest (ROI) was measured as described by Villamonte et 
Dog breeds, gender, age and bodyweight included in the study

\begin{tabular}{|c|c|c|c|c|c|c|c|}
\hline \multirow[b]{2}{*}{ Breed } & \multirow[b]{2}{*}{$\mathrm{D}$} & \multirow[b]{2}{*}{$\mathrm{C}$} & \multirow[b]{2}{*}{ Total } & \multicolumn{2}{|c|}{ Gender } & \multirow{2}{*}{$\begin{array}{l}\text { Average age } \\
\text { (months) }\end{array}$} & \multirow{2}{*}{$\begin{array}{c}\text { Average } \\
\text { bodyweight }\left(\mathrm{kg}^{-1}\right)\end{array}$} \\
\hline & & & & male & female & & \\
\hline German shepherd dog & 19 & 7 & 26 & 19 & 7 & 18.1 & 32.2 \\
\hline Labrador retriever & 24 & 2 & 26 & 18 & 8 & 20.4 & 26.8 \\
\hline Golden retriever & 3 & 9 & 12 & 7 & 5 & 22.9 & 29.6 \\
\hline Bernese mountain dogs & 8 & 2 & 10 & 3 & 7 & 27.6 & 39.2 \\
\hline Mix breed & 5 & - & 5 & 5 & 0 & 12.4 & 30.7 \\
\hline Landseer & 1 & - & 1 & 0 & 1 & 22 & 48 \\
\hline Newfoundland dog & 2 & - & 2 & 1 & 1 & 10 & 61 \\
\hline Rottweiler & 2 & - & 2 & 1 & 1 & 8.5 & 22.5 \\
\hline Cane Corso & - & 3 & 3 & 2 & 1 & 13.3 & 42.7 \\
\hline Pyrenean mountain dog & - & 1 & 1 & 1 & 0 & 12 & 53 \\
\hline Central Asian shepherd dog & 1 & 1 & 2 & 1 & 1 & 6 & 45 \\
\hline Bordeaux dog & - & 1 & 1 & 0 & 1 & 6 & 28 \\
\hline Total & 65 & 26 & 91 & 58 & 33 & 15.75 & 38.2 \\
\hline
\end{tabular}

$\mathrm{D}$ - dogs with a medial coronoid disease, $\mathrm{C}$ - control group dogs.

al. (2016). Using this method ROI values in HU were determined in a sagittal plane at the level of MCP base and apex. In each level HU, we determined at two ROIs (Villamonte-Chevalier et al., 2016). The second technique (B) was created by authors of this paper. In a technique (B) to detect radiodensity of a medial coronoid process, HU was measured at the level of a medial coronoid base. To obtain the suitable sagittal image corresponding to the MCP base, the humeral condyle on the axial plane was used as the reference. At this level sagittal reconstruction line was set in the middle of humeral condyle. At the beginning in the sagittal reconstruction two perpendicular lines were drawn - one line $(\alpha)$ from ulna proximal metaphysis caudal margin at the level of MCP to the caudal part of the ulna. The second line $(\beta)$ was drawn at the level of radius epiphysis to the caudal ulna. An area between line $\alpha$ and line $\beta$ was our ROI in this method. Hounsfield units in ROIs were measured with Horos v2.2.0 software closed polygon function. All measurements were performed excluding cortex of the ulna.

\section{Statistical analysis}

Descriptive statistic were used to describe computed tomography findings. ROIs average values were compered between normal joints and MCD joints using t-test two sample assuming unequal variances with the significance level set at 95\% $(\mathrm{p}<0.05)$. Correlation analyses were performed to evaluate the effect of age, bodyweight, and breed on MCP radiodensity.

\section{Results and Discussion}

The medial coronoid disease we diagnosed in 65 dogs. Bilateral MCD in 42 (64.6\%) dogs and 23 (25.4\%) dogs had unilateral MCD. Total 107 elbow joints were with a medial coronoid disease. In the control group, we included 52 normal elbow joints from 26 dogs.

Subchondral sclerosis was diagnosed in 85 elbow joints and in $91.8 \%$ of the cases they were together with MCP fragmentation and fissure. MCP intraarticular fragmentation was diagnosed more often than MCP fissure. Arthrosis we diagnosed in 27 cases and in 24 cases it was together with intraarticular medial coronoid fragmentation. No significant correlation was detected between MCD findings and canine age, gender, breed, and bodyweight $(\mathrm{r}<0.2)$. Computed tomography finding occurrence is presented in Figure I.

Our study included dog breeds equivalent to previous studies, where it is stated that German shepherd dogs, Labrador retrievers, Golden retrievers and Rottweilers are prevented from MCD (Hazewinkel, 2014; Morgan, Wind, \& Davidson, 1999; Remy et al., 2004). All these breeds were included in our study, with a prevalence of German shepherd dogs and Labrador retrievers. All included dogs in our study were up to 30 months old, because this disease affects more often young dogs (Remy et al., 2004). Our practical experience shows that dogs after the three years of age very often have secondary joint degeneration that cannot be related with an MCD. For this reason, we did not include dogs over three years of age. Also, we did not include dogs under 6 months since in large 


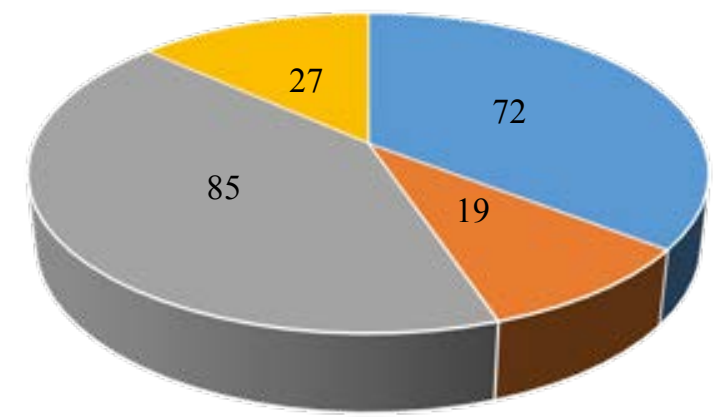

- MCP fragment

- Subchondral sclerosis
- MCP fissure

- Osteophytosis

Figure 1. Computed tomography findings in dogs with a medial coronoid disease.

breed dogs MCP endochondral ossification are closing at the age of 20 to 22 weeks (Breit, Künzel, \& Seiler, 2004). In our study, males were more often affected than females and that coincides with the information available from other studies (Meyer-Lindenberg, Fehr, \& Nolte, 2006). At the control group, we tried to provide similar proportion. Although many studies have previously been done, it is not fully clear why male dogs are more often affected by MCD than female ones.

\section{Technique (A)}

According to the Villamonte et al. (2016) Hounsfield unit measurement method, ROI 1 and ROI 2 present HU in the MCP apex, but ROI 3 and ROI 4 HU in an MCP base. All ROI values are presented in Table 2.

Statistical calculation results showed that between normal joint and MCD joint ROI values there is statistically significant difference in all ROI values (ROI $1 \mathrm{p}=0.002$; ROI $2 \mathrm{p}=0.0003$; ROI $3 \mathrm{p}=0.008$; ROI $4 \mathrm{p}=0.001)$.
Correlation analysis presented a negative weak correlation between ROI 1 ( $\mathrm{r}=-0.37)$, ROI 2 ( $\mathrm{r}=-0.28$ ) values and dog gender, but no significant correlation $(\mathrm{r}<0.2)$ between the rest ROI values and dog gender, bodyweight, age, and breed. In addition, we analysed the correlation between ROI values and MCD findings and found that correlation $(\mathrm{r}<0.2)$ between these parameters is very weak and insignificant.

In our clinical cases, a correlation between MCP $\mathrm{HU}$ and dog age, gender, breed, and bodyweight was not observed. However, Villamonte et al. (2016) points that in previous study Labrador retrievers had higher HU values than Golden retrievers. We determined that in our cases the significant difference was in all ROI values between normal joints and MCD joints, but the biggest difference was at the level of ROI $2(p=0.0003)$. However, it does not coincide with previous studies where the most representative region was a medial coronoid process base (MCPB2) - ROI 4 (Villamonte et al., 2016).

Medial coronoid process Hounsfield unit values of ROI by the first method

Table 2

\begin{tabular}{|c|c|c|c|c|c|c|}
\hline \multirow[b]{2}{*}{ Parameters } & \multicolumn{3}{|c|}{ Joints with MCD } & \multicolumn{3}{|c|}{ Normal joints } \\
\hline & $\begin{array}{l}\text { right elbow } \\
\mathrm{X} \pm \mathrm{SD}\end{array}$ & $\begin{array}{l}\text { left elbow } \\
\mathrm{X} \pm \mathrm{SD}\end{array}$ & $\begin{array}{c}\text { Both elbows } \\
\mathrm{X} \pm \mathrm{SD}\end{array}$ & $\begin{array}{l}\text { right elbow } \\
\mathrm{X} \pm \mathrm{SD}\end{array}$ & $\begin{array}{l}\text { left elbow } \\
X \pm S D\end{array}$ & $\begin{array}{c}\text { Both elbows } \\
\mathrm{X} \pm \mathrm{SD}\end{array}$ \\
\hline ROI 1 & $\begin{array}{c}845.01 \pm \\
177.752 \\
\end{array}$ & $\begin{array}{c}832.82 \pm \\
219.372 \\
\end{array}$ & $\begin{array}{c}834.07 \pm \\
201.540 \\
\end{array}$ & $\begin{array}{c}647.82 \pm \\
194.200 \\
\end{array}$ & $\begin{array}{c}665.83 \pm \\
196.743 \\
\end{array}$ & $\begin{array}{c}656.92 \pm \\
42.594 \\
\end{array}$ \\
\hline ROI 2 & $\begin{array}{c}666.69 \pm \\
271.268 \\
\end{array}$ & $\begin{array}{c}596.90 \pm \\
199.995 \\
\end{array}$ & $\begin{array}{c}631.79 \pm \\
238.021 \\
\end{array}$ & $\begin{array}{c}427.13 \pm \\
148.523 \\
\end{array}$ & $\begin{array}{c}442.55 \pm \\
177.711 \\
\end{array}$ & $\begin{array}{c}434.84 \pm \\
35.686 \\
\end{array}$ \\
\hline ROI 3 & $\begin{array}{c}1,080.31 \pm \\
255.478\end{array}$ & $\begin{array}{c}1,081.91 \pm \\
179.876\end{array}$ & $\begin{array}{c}1,081.11 \pm \\
218.226\end{array}$ & $\begin{array}{l}911.98 \pm \\
231.224\end{array}$ & $\begin{array}{c}923.64 \pm \\
209.132\end{array}$ & $\begin{array}{c}917.81 \pm \\
47.990\end{array}$ \\
\hline ROI 4 & $\begin{array}{c}862.31 \pm \\
215.327 \\
\end{array}$ & $\begin{array}{l}805.81 \pm \\
259.003 \\
\end{array}$ & $\begin{array}{c}834.06 \pm \\
236.980\end{array}$ & $\begin{array}{c}568.47 \pm \\
255.556 \\
\end{array}$ & $\begin{array}{c}576.38 \pm \\
334.166 \\
\end{array}$ & $\begin{array}{c}572.42 \pm \\
64.748 \\
\end{array}$ \\
\hline Apex & \multicolumn{3}{|c|}{$732.92 \pm 241.665$} & \multicolumn{3}{|c|}{$656.82 \pm 188.028$} \\
\hline Base & \multicolumn{3}{|c|}{$957.58 \pm 258.278$} & \multicolumn{3}{|c|}{$745.11 \pm 306.405$} \\
\hline
\end{tabular}

$\mathrm{X}$ - average value, $\mathrm{SD}$ - standard deviation. 


\section{Technique (B)}

In the second method, HU was measured in one area at the level of MCP base. The average HU value in dogs with an MCD was $1058.06 \pm 113.831$ and $306.19 \pm 119.963$ in normal joints. In both groups, not significant difference $(p=0.726)$ was detected between right and left elbow joint. T-test results showed the significant difference $(p<0.0001)$ in $\mathrm{HU}$ between joints with an MCD and normal joints. Correlation analysis shows that between MCP radiodensity and dog's age, gender, bodyweight, and breed correlation $(r<0.2)$ is very weak.

Comparing the technique (A) and technique (B) we consider that there are common and disparate things between both methods. The main common fact is that regardless of the method Hounsfield values in MCD affected joints were at least $15 \%$ higher than in healthy elbows joints in all MCP zones. The statistically significant difference $(p<0.0001)$ was between the technique (A) all ROIs values and technique (B) data. That indicates that these techniques are not comparable between themselves and should be assessed separately.

\section{Conclusions}

1. Medial coronoid process subchondral sclerosis in our study was the most frequently diagnosed pathology in dogs with a medial coronoid disease and mostly encounter with a fragmentation of a medial coronoid process and can be considered as an early indicator of a medial coronoid disease.

2. A significant correlation between medial coronoid process radiodensity and dog`s age, bodyweight and breed does not exist.

3. Technique (A) radiodensity measurement method is useful in a veterinary diagnostic imaging and can be used to distinguish subchondral sclerosis affected joints and all ROI values are enough sensitive to confirm diagnosis.

4. Technique (B) is quick and sensitive method to determine subchondral sclerosis of dogs with a medial coronoid process and can be used in a clinical practice.

5. First and second methods are unrelated and Hounsfield unit values cannot be compered between.

\section{References}

1. Breit, S., Künzel, W., \& Seiler, S. (2004). Variation in the ossification process of the anconeal and medial coronoid processes of the canine ulna. Research in Veterinary Science, 77(1), 9-16. DOI: 10.1016/j. rvsc.2004.02.003.

2. Gemmill, T.J., Hammond, G., Mellor, D., Sullivan, M., Bennett, D., \& Carmichael, S. (2006). Use of reconstructed computed tomography for the assessment of joint spaces in the canine elbow. Journal of Small Animal Practice, 47(2), 66-74. DOI: 10.1111/j.1748-5827.2006.00052.

3. Hazewinkel, D. (2014). Elbow Dysplasias: different entities and their etiologies, incidence and prevalence and genetic aspects. In 28th annual meeting of the INTERNATIONAL ELBOW WORKING GROUP. Cape Town. Retrieved February 10, 2018, from: http://www.vet-iewg.org/wp-content/uploads/2017/02/ proceedings2014.pdf.

4. Hurlbeck, C., Einspanier, R., Pfeil, I., \& Bondzio, A. (2014). Evaluation of biomarkers for osteoarthritis caused by fragmented medial coronoid process in dogs. Research in Veterinary Science, 96(3), 429-435. DOI: 10.1016/j.rvsc.2014.02.012.

5. Lavrijsen, I.C.M., Heuven, H.C.M., Meij, B.P., Theyse, L.F.H., Nap, R.C., Leegwater, P.A.J., \& Hazewinkel, H.A.W. (2014). Prevalence and co-occurrence of hip dysplasia and elbow dysplasia in Dutch pure-bred dogs. Preventive Veterinary Medicine, 114(2), 114-122. DOI: 10.1016/j.prevetmed.2014.02.001.

6. Meyer-Lindenberg, A., Fehr, M., \& Nolte, I. (2006). Co-existence of ununited anconeal process and fragmented medial coronoid process of the ulna in the dog. Journal of Small Animal Practice, 47(2), 61-65. DOI: 10.1111/j.1748-5827.2006.00051.

7. Morgan, J., Wind, A., \& Davidson, A. (1999). Bone dysplasias in the labrador retriever: a radiographic study. Journal of the American Animal Hospital Association, 35(4), 332-340. DOI: 10.5326/1547331735-4-332.

8. Remy, D., Neuhart, L., Fau, D., \& Genevois, J.P. (2004). Canine elbow dysplasia and primary lesions in German shepherd dogs in France. Journal of Small Animal Practice, 45(5), 244-248. DOI: 10.1111/ j.1748-5827.2004.tb00230.

9. Samoy, Y., Gielen, I., Bree, H. Van, \& Ryssen, B. Van. (2011). Dysplastic elbow diseases in dogs Elleboogdysplasie bij honden. Vlaams Diergeneeskundig Tijdschrift, 80, 327-338. Retrieved February 10, 2018, from: http://www.vdt.ugent.be/sites/default/files/art80502.pdf.

10. Smith, T.J., Fitzpatrick, N., Evans, R.B., \& Pead, M.J. (2009). Measurement of ulnar subtrochlear sclerosis using a percentage scale in labrador retrievers with minimal radiographic signs of periarticular osteophytosis. Veterinary Surgery, 38(2), 199-208. DOI: 10.1111/j.1532-950X.2008.00488. 
11. Vermote, K.A.G., Bergenhuyzen, A.L.R., Gielen, I., van Bree, H., Duchateau, L., \& Van Ryssen, B. (2010). Elbow lameness in dogs of six years and older: arthroscopic and imaging findings of medial coronoid disease in 51 dogs. Veterinary and Comparative Orthopaedics and Traumatology: V.C.O.T, 23(1), 43-50. DOI: 10.3415/VCOT-09-03-0032.

12. Villamonte-Chevalier, A., Dingemanse, W., Broeckx, B.J.G., Van Caelenberg, A., Agut, A., Duchateau, L., \& Gielen, I. (2016). Bone density of elbow joints in Labrador retrievers and Golden retrievers: Comparison of healthy joints and joints with medial coronoid disease. Veterinary Journal, 216, 1-7. DOI: 10.1016/j. tvjl.2016.06.005.

13. Villamonte-Chevalier, A., van Bree, H., Broeckx, B., Dingemanse, W., Soler, M., Van Ryssen, B., \& Gielen, I. (2015). Assessment of medial coronoid disease in 180 canine lame elbow joints: a sensitivity and specificity comparison of radiographic, computed tomographic and arthroscopic findings. BMC Veterinary Research, 11(1), 243. DOI: 10.1186/s12917-015-0556-9. 